\title{
A TRADUÇÃO INTERSEMIÓTICA NA ELABORAÇÃO DE BRINQUEDO PEDAGÓGICO DESTINADO AO PROCESSO DE ALFABETIZAÇÃO E LETRAMENTO DE CRIANÇAS CEGAS A PARTIR DA OBRA “OS TRÊS PORQUINHOS”
}

\author{
THE INTERSEMIOTIC TRANSLATION IN THE PREPARATION OF A PEDAGOGICAL TOY \\ INTENDED FOR THE PROCESS OF LITERACY AND LETTERING OF BLIND CHILDREN \\ FROM THE WORK "THE THREE PORQUINHOS"
}

DAGOSTIM, Cristiane Gonçalves; Doutora; Universidade do Sul de Santa Catarina e Faculdade Satc cris.dagostim@gmail.com

NESI, Flávia Aparecida; Bacharel; Faculdade Satc

nesi.flavia@gmail.com

\section{Resumo}

Este estudo busca relatar a importância da tradução intersemiótica na elaboração de brinquedo destinado ao processo de alfabetização e letramento de crianças cegas, aplicando-o a alunos com necessidades especiais da Escola Básica São Cristóvão, de Criciúma/SC. O propósito desta pesquisa é o de buscar as contribuições do Design por meio da tradução intersemiótica na elaboração do recurso pedagógico. A pesquisa é relevante, pois envolve fatores e dados reais de problemas, possibilitando a busca por solução, bem como mostra a importância do design na área educacional. A fundamentação teórica foi embasada nos estudos de semiótica, tradução intersemiótica e suas classificações, na importância do brincar e da ludicidade e também nas concepções de alfabetização e letramento. A obra "Os Três Porquinhos", de Joseph Jacobs, foi fundamental e basilar para o desenvolvimento do brinquedo destinado ao letramento. $O$ produto final foi aplicado e validado, seus resultados foram positivos e se mostraram relevantes às crianças que o utilizaram, assim como para os objetivos propostos nesta pesquisa.

Palavras Chave: Tradução intersemiótica. Deficiência visual. Alfabetização. Letramento.

\begin{abstract}
This study aims to report the importance of intersemiotic translation in the elaboration of a toy destined to the process of literacy and literacy of blind children, applying it in a special class of Criciúma / SC Basic School of São Cristóvão. The purpose of this research is to seek the contributions of Design through intersemiotic translation in the elaboration of the pedagogical resource. The research is relevant, because it involves real factors and data of problems, enabling the search for solution, as well as shows the importance of design in the educational area. The theoretical basis was based on studies of semiotics, intersemiotic translation and their classifications, on the importance of play and playfulness, as well as on literacy and literacy conceptions. For this project, the work "The Three Little Pigs" by Joseph Jacobs was fundamental
\end{abstract}


and basis for the development of the toy for literacy. The product was applied and validated, its results were positive and were relevant to the children who used it, as well as to the objectives proposed in this research.

Keywords: Intersemiotic translation. Visual impairment. Literacy. Literature.

\section{Introdução}

A deficiência visual é uma condição que afeta uma parte significativa da população e, segundo dados da Organização Mundial da Saúde (WHO, 2010), estima-se que em todo o mundo existem 314 milhões de pessoas com algum tipo de deficiência visual, sendo que 45 milhões delas sofrem de cegueira.

No Brasil, o Censo de 2010, realizado pelo Instituto Brasileiro de Geografia e Estatística, aponta que mais de 6,5 milhões de pessoas têm algum tipo de deficiência visual, das quais 528 mil são cegas. Para cada grupo de 100 crianças de 0 a 14 anos de idade, 5,3\% apresentam alguma deficiência visual (IBGE, 2010).

Diante dos dados, percebeu-se a necessidade de projetos e produtos acessíveis para esse público, buscando-se formas que promovam a inclusão e a acessibilidade desses cidadãos a partir de projetos acessíveis.

O presente estudo tem como foco crianças e adolescentes com total ausência de visão, em idade de alfabetização e letramento, visando a proporcionar o conhecimento do gênero discursivo conto de forma lúdica. Para o desenvolvimento da pesquisa, faz-se necessário o entendimento da semiótica, dos signos e da tradução intersemiótica para responder a seguinte questão: Como a tradução intersemiótica pode auxiliar no processo de alfabetização e letramento de crianças cegas a partir da obra "Os Três Porquinhos"?

O objetivo geral do estudo é elaborar um brinquedo destinado ao processo de alfabetização e letramento de crianças cegas a partir da tradução intersemiótica do conto "Os Três Porquinhos". Para isso, tem como objetivos específicos: fundamentar os conceitos de semiótica (PEIRCE, 2010), tradução intersemiótica (PLAZA, 2016), alfabetização e letramento (SOARES, 2013); a importância do brinquedo e da ludicidade na educação infantil (SCHEFFER, 2010); estudar e aplicar a tradução intersemiótica na elaboração de um brinquedo destinado ao processo de alfabetização e letramento de crianças cegas; e contar a história Os Três Porquinhos por meio de um brinquedo interativo.

O trabalho é de importância para a sociedade, pois se entende que o estudo em questão se volta à inclusão social por meio do acesso às histórias infantis e ao reconhecimento de imagens táteis por crianças em fase de alfabetização e letramento. Além disso, poderá despertar o interesse de outros designers para a criação de materiais voltados às deficiências e trazer novas possibilidades de pesquisa para o mercado e para a comunidade acadêmica.

\section{Fundamentação}

No século $X X$, nasceram e tiveram ascensão duas ciências da linguagem: a linguística, ciência da linguagem verbal; e a semiótica, ciência de toda e qualquer linguagem (SANTAELLA, 
1983).

Charles Sanders Peirce é conhecido como um dos precursores ao transformar o estudo dos signos em uma ciência. Conhecida como semiótica, estuda todos os tipos de linguagens, desde a verbal, até a não verbal, visto que: "A Semiótica é a ciência geral de todas as linguagens" (SANTAELLA, 1983, p.7).

O principal intuito da semiótica, de acordo com Niemeyer (2009), é permitir a descrição e a análise de uma representação significativa, ou seja, conhecer a estruturação sígnica de um sistema e conseguir interpretá-lo.

Os sistemas de comunicação da humanidade não se restringem apenas ao sistema verbal, falar ou escrever. De acordo com os estudos de Santaella (1983), o ser humano também se comunica por meio de diversas formas gráficas e imagens, de objetos, de sentimentos e sentidos humanos como: tato, olfato e paladar.

Niemeyer (2009) ressalta a importância da semiótica no processo de design, uma vez que fornece uma base teórica para a resolução de questões comunicacionais, ou seja, como o produto vai se comunicar com o usuário. Sendo assim, o estudo de todo e qualquer tipo de linguagem é o principal objetivo da semiótica.

Por meio do estudo dos signos, compreende-se o valor que eles representam na interpretação e tradução semiótica. Para Jakobson (2011), existem três modos de interpretar um signo verbal, que podem ser classificados como: a tradução intralingual, que ocorre dentro de uma mesma língua; a tradução interlingual, que ocorre de uma língua para outra; e, a tradução intersemiótica, que traduz algo de um sistema de signos para outro, sendo esta a que fundamentará o desenvolvimento deste estudo.

\subsection{Tradução Intersemiótica a partir de Plaza}

Plaza (2016) explica que a tradução intersemiótica consiste na representação de um sistema de signos para outro. Segundo Jakobson (2011, p.43), "A tradução intersemiótica, ou transmutação, consiste na interpretação dos signos verbais por meio de sistemas de signos nãoverbais". Plaza (2016) classifica a tradução intersemiótica em três princípios de tradução: a Tradução Intersemiótica como Intercurso dos Sentidos, como Transcrição de Formas e como Pensamento em Signos. Para atender as necessidades do estudo, este trabalho abordará a Tradução como Intercurso dos Sentidos e como Pensamento em Signos.

A Tradução Intersemiótica como Intercurso dos Sentidos trata dos sentidos que são utilizados para traduzir pensamentos. Segundo Plaza (2016), os sistemas de sinais articulados pelos órgãos emissores-receptores produzem as mensagens que reproduzem os sentidos, promovendo a comunicação dos homens entre si. Ao longo da história, os sentidos (visual, tátil e auditivo) geraram os meios produtores dos sistemas de linguagem.

Plaza (2016, p.48) afirma que a rede entre os sentidos e o "consequente embutimento de um meio dentro de outro" é o que fundamenta e possibilita a Tradução Intersemiótica como intercurso dos sentidos, ou trânsito de meios, canais, suportes e códigos, e é através desses meios que acontece a tradução do objeto dinâmico em objeto imediato.

Para Plaza (2016), toda vez que um signo é produzido, surge um objeto imediato que é caracterizado pelas qualidades materiais dos meios e linguagens, utilizando-se dos sentidos da 
visão, do tato, da audição, do olfato, dentre outros. Neste estudo, serão abordados o tato e a audição, uma vez que serão feitas as traduções da linguagem escrita para os meios tátil e acústico.

Acredita-se que, apesar do sentido visual ser dominante culturalmente, é o tato o primeiro sentido que se manifesta, aparecendo desde cedo na vida fetal e infantil com a exploração do próprio corpo. A exploração tátil é ainda responsável por fornecer ao cego a orientação espacial, sendo que as formas hápticas realizadas por cegos têm mais sentido do que as mesmas formas realizadas por videntes (PLAZA, 2016).

Conforme Plaza (2016), o espaço acústico tem um caráter mais qualitativo e analógico do que o visual, além de proporcionar experiências muito diferentes, pois no meio visual se pode selecionar a informação e, no meio acústico, percebe-se simultaneamente os sons, dificultando a localização da fonte emissora.

A Tradução Intersemiótica como Transcrição de Formas trata da transcrição de um signo de uma forma para outra. Segundo Plaza (2016), na tradução intersemiótica como transcrição de formas, o legissigno semiótico é responsável por exercer a função de norma e estrutura, dando significação a essa forma, possibilitando o reconhecimento de semelhanças e diferenças entre a obra original e a tradução.

Para analisar as diferentes atividades dentro do signo, Plaza (2016) toma como base o intracódigo que é classificado em duas atividades sígnicas: a contiguidade e a semelhança. A atividade sígnica por contiguidade é aquela na qual o signo original cede passagem a outro diferente, mas é parte dele, e é dividida em três principais modalidades: contiguidade topológica, contiguidade por referência e contiguidade por convenção. Na atividade sígnica por semelhança, as partes do signo mantêm entre si relações de similaridade e também possuem três modalidades: semelhança de qualidades, semelhança por justaposição e semelhança por mediação.

Plaza (2016) destaca a importância do intracódigo para a tradução, pois é o responsável pela configuração das relações internas da linguagem com base nas classes dispostas por Peirce (2010), que foi quem desenvolveu três tipologias de tradução.

\subsection{Tipologias das Traduções}

As tipologias da tradução intersemiótica foram divididas por Plaza (2016), segundo seus grupos de legissignos, em três matrizes de tradução: Tradução Icônica, Tradução Indicial e Tradução Simbólica.

A tradução icônica está pautada no princípio de similaridade e no da analogia entre os objetos imediatos, produzindo significados na forma de qualidades e aparências entre ela e seu original, sendo assim, uma transcrição.

A tradução indicial faz uma relação de contiguidade entre o objeto imediato e a tradução, originando o processo de transposição de um meio a outro.

E a tradução simbólica se dá por meio de metáforas, símbolos, códigos e outros signos de atributos convencionais, em que o signo dará surgimento a outro signo na visão do intérprete, promovendo uma transcodificação, ou seja, uma transferência de códigos.

A pesquisa será embasada nas traduções icônica, indicial e simbólica, conforme seguem na metodologia de projeto, e inicialmente será necessário o entendimento da importância da brincadeira no desenvolvimento infantil e na pedagogia. 


\subsection{O Design e o Lúdico}

O design se faz presente em todos os âmbitos, desde a aquisição de bens de consumo até o desenvolvimento da formação social e cultural de uma sociedade.

Para Ferreira e Santos (2014), trata-se de uma atividade projetual e processual que dá origem a produtos que auxiliam na interação entre as pessoas, sendo um meio de comunicação relacionado a uma produção em massa. Enquanto o design reflete a realidade de uma cultura aliando valores estéticos e aspectos funcionais de um produto, o design lúdico transcende o aspecto funcional e se ocupa em tornar a relação entre o produto e o usuário mais agradável e divertida. Objetiva ainda o desenvolvimento dos aspectos afetivo, motor, mental, intelectual e social do indivíduo.

A ludicidade está presente em várias fases do desenvolvimento humano e social, possibilita a aprendizagem e o conhecimento por meio de brinquedos, jogos e brincadeiras.

Segundo Maluf (2008, p. 21), a atividade lúdica é "toda e qualquer animação que tem como intenção causar prazer e entretenimento em quem a pratica". Dessa forma, as atividades lúdicas, na infância, favorecem o desenvolvimento psicológico, a socialização e a troca de experiências, tornando-se uma importante ferramenta para a prática pedagógica e auxiliando no processo de alfabetização e letramento.

Para viver em sociedade e se comunicar com os meios, é fundamental saber ler e escrever, sendo a leitura e a escrita a base de quase toda forma de comunicação e primordiais para a formação acadêmica, para a vida profissional e para os relacionamentos interpessoais.

No sentido da aquisição das habilidades de leitura e escrita, faz-se necessário o processo de alfabetização e letramento que, apesar de serem entendidos como processos distintos, se complementam: a pessoa alfabetizada é aquela que sabe ler e escrever e a pessoa letrada é aquela que faz uso social da escrita nos diferentes meios e situações (SOARES, 2013).

A autora (2013, p. 35) ainda define a alfabetização como o processo de aquisição do código escrito, da leitura e da escrita, e descreve a palavra "letramento" como a tradução para o português da palavra inglesa literacy, que quer dizer "a condição de ser letrado", ou seja, é o indivíduo que não sabe apenas ler e escrever, mas pratica atividades que utilizam a escrita.

Ainda sobre alfabetização e letramento, Tfouni (2002) relata que, à medida que a alfabetização exerce o ensino da escrita para um indivíduo, o letramento abrange a escrita em conjunto com as questões sociais e econômicas da sociedade. Todavia, letrado não requer, necessariamente, a condição de ser alfabetizado, ou seja, crianças não alfabetizadas podem ser inseridas em um processo de letramento por fazerem a leitura casual de imagens, gestos e emoções.

Conforme a Secretaria de Educação Especial/MEC (2012, p.27): "ser alfabetizado é um direito social constituído e conquistado historicamente. Assim, na medida em que, no Brasil, política e pedagogicamente, cada criança tem o direito fundamental de estar alfabetizada, até os oito anos de idade". O MEC ainda propõe políticas e ações que garantam o direito de acesso e permanência de alunos com necessidades educacionais especiais, orientando sobre a inclusão desses indivíduos, preferencialmente, na rede regular de ensino, como menciona a Lei de 
Diretrizes e Bases da Educação Nacional (LDBEN) № 9394 de 20 de dezembro de 1996.

Segundo a Constituição Federal do Brasil de 1988 no art. 205, a educação é um direito de todos, sendo um dever do Estado e da família em conjunto com a sociedade, objetivando ao cidadão o desenvolvimento pessoal, o exercício da cidadania e a qualificação para o trabalho. Porém, faltam subsídios para tornar essas exigências legais uma realidade para todas as crianças, em especial às com necessidades educacionais especiais.

Dessa forma, cabe à sociedade e aos órgãos responsáveis encontrar formas de facilitar a inclusão e educação de crianças cegas, pois normalmente é somente por meio do Sistema Braille que elas têm noções da escrita das palavras. Segundo Almeida (2017), as crianças cegas só têm contato com a escrita e com a leitura no período escolar, desse modo, o Sistema Braille pouco se relaciona ao dia a dia delas, tornando impraticáveis as descobertas das propriedades e funções da escrita.

Sobre o desenvolvimento pedagógico de crianças cegas, é importante o estímulo com brincadeiras, materiais adaptados às necessidades e recursos diversos. Dentre estes, a literatura infantil surge como ferramenta significativa nesse processo de desenvolvimento.

\subsection{Literatura Infantil}

A literatura infantil historicamente surgiu da necessidade do homem em transmitir a sua cultura e seus conhecimentos para seus descendentes por meio da contação de histórias.

O início da literatura infantil se dá entre os anos de 1628 e 1703, com Charles Perrault e as obras "Mãe Gansa", "O Barba Azul", "Cinderela", "A Gata Borralheira", "O Gato de Botas" e outros. Pouco depois, apareceram os seguintes escritores: Andersen, Collodi, Irmãos Grimm, Lewis Carrol, Bush. Já no Brasil, a literatura infantil tem seu início com o livro de Andersen, no século XX: "O Patinho Feio". Logo depois, surgiu Monteiro Lobato com seu primeiro livro: "Narizinho Arrebitado" e, com muitos outros que até hoje encantam milhares de crianças, despertando o gosto e o prazer da leitura (CADEMARTORI, 1994).

Desde então, a contação de histórias e os livros infantis são utilizados por pais e professores para alfabetizar, educar e entreter, proporcionando a relação entre o mundo real e o lúdico. Todavia, nem sempre esses livros oportunizam as crianças cegas, bem como os jogos a eles relacionados.

Para Scheffer (2010), a literatura está presente nas brincadeiras e rodas cantadas, na arte e nos filmes infantis, combinada com as atividades lúdicas e promovendo o desenvolvimento da criança, a imaginação, a criatividade e seu senso crítico. $E$, além de ser utilizada nas escolas como recurso pedagógico de auxílio no aprendizado da linguagem escrita, contribui também com a fruição estética nas crianças.

Uma criança cega pode manipular um livro infantil, afirma Preto (2009), porém, não terá a mesma decodificação de sua história como os outros alunos, por não interpretar as informações da mesma forma como uma criança vidente. Ela utiliza os outros sentidos, ou seja, a linguagem oral, a leitura tátil, auditiva e até mesmo olfativa de um livro, decodificando um texto por meio de outros sentidos, mesmo que não saiba ler.

Para o autor (2009), há uma grande importância na adaptação de livros de literatura infantil para crianças deficientes visuais, pois a experiência e o contato com os diferentes livros 
oferece oportunidade e acesso à leitura, o aprendizado de diferentes conceitos e de novas estruturas linguísticas.

Com a finalidade de gerar novas oportunidades de aprendizado, este projeto busca utilizar do design e da ludicidade na elaboração de recurso pedagógico por meio da tradução intersemiótica da obra "Os três porquinhos".

\section{Metodologia}

Como objetivo de organizar em etapas o processo de desenvolvimento do projeto, a fim de facilitar o processo de pesquisa e a obtenção dos resultados propostos, optou-se pela metodologia projetual de tradução intersemiótica aplicada ao design gráfico elaborada por Medeiros et. al. (2016), que consiste em um método com base em seis etapas distintas e definidas (Fig. 1), que buscam sistematizar e organizar as etapas de uma tradução intersemiótica.

Figura 1 - As seis etapas da metodologia e suas relações
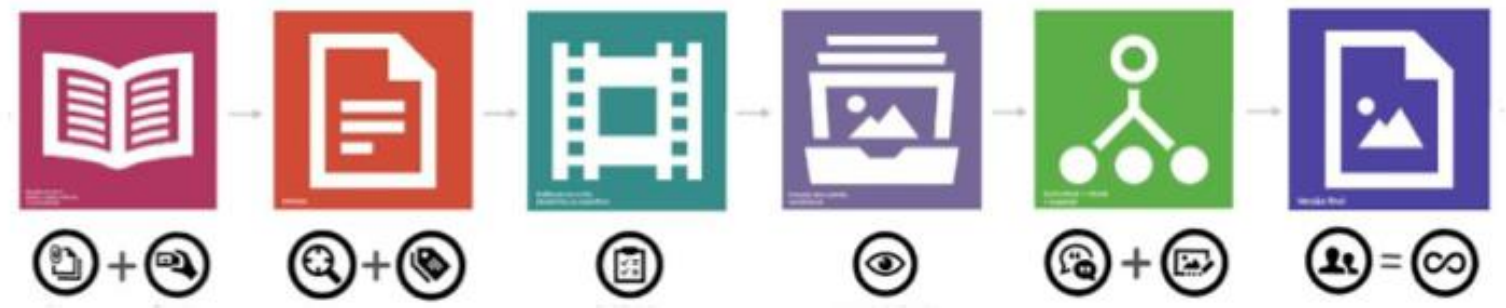

Fonte: Medeiros et al. (2016)

As seis etapas da metodologia consistem em necessidade de projeto, conceitos-chave, mídia, painéis, geração de alternativas e soluções e validação, que serão detalhadas durante o desenvolvimento do projeto com algumas alterações para facilitar a tradução.

A obra "Os Três Porquinhos" é um conto infantil que teve adaptações para o cinema e para alguns brinquedos e livros em Braille. No estudo em questão, objetiva-se traduzir a obra de modo que crianças cegas possam fazer a leitura por meio dos sentidos táteis e auditivos simultaneamente e, para tanto, buscou-se a aplicação da tradução intersemiótica como metodologia, de acordo com as etapas da metodologia projetual de Medeiros et. al. (2016).

\subsection{Necessidade do Projeto}

Esta etapa é fundamental para conhecer e analisar o texto a ser traduzido e coletar informações para o briefing. Este que, por sua vez, auxiliará no processo de tradução indicial, pois possui as orientações do projeto.

No projeto, esta etapa foi estruturada da seguinte forma: entrevista com a professora de Braille da Escola Básica São Cristóvão, de Criciúma; análise e coleta de dados das respostas; pesquisas complementares; adaptação da obra "Os Três Porquinhos", de Joseph Jacobs.

Inicialmente, foi feita uma entrevista com a professora de Braille Daiana de Assis, da escola Básica São Cristóvão, com o objetivo de avaliar o atual cenário do processo de alfabetização e letramento de alunos cegos, gerar as informações para o briefing e coletar as informações sobre 
as necessidades do projeto.

De acordo com a entrevista realizada com a professora, a escola possui dois alunos cegos que frequentam as aulas juntamente com os alunos do ensino fundamental e são alfabetizados em braille. Nesse processo, os alunos recebem os materiais em braile traduzidos por ela e possuem a reglete braille, assim conseguem responder questões discursivas acerca dos assuntos estudados, que são novamente traduzidos e entregues à professora do ensino fundamental.

Ela relata as dificuldades enfrentadas quanto à necessidade em explicar aos alunos sobre assuntos mais abstratos como a luz, a cor, as estrelas, ou seja, sobre tudo aquilo que só é possível entender quando se tem o sentido da visão. E também descreve a falta de materiais adaptados para facilitar o processo de entendimento dos alunos acerca dos assuntos mencionados e das disciplinas, explicando que normalmente ela desenvolve os materiais e recursos para auxiliar no processo de alfabetização e letramento.

Com os dados obtidos na entrevista, foi possível identificar e definir algumas características do brinquedo pedagógico a ser desenvolvido e buscar maior aprofundamento por meio de pesquisas complementares sobre o assunto em livros, sites e referências.

A partir da adaptação da obra "Os Três Porquinhos", de Joseph Jacobs do livro Clássicos de Ouro: Os Três Porquinhos da editora Todolivro, em um resumo de seis cenas principais, gerou-se a gravação em voz que foi utilizada como componente sonoro e adaptado ao brinquedo por meio de um circuito microprocessado.

\subsection{Conceitos-chave}

A segunda etapa é a de desenvolvimento de conceitos-chave, que acontece quando, com o auxílio de algumas ferramentas e técnicas, gera-se uma síntese da leitura do texto e das informações do briefing. Nessa etapa, coleta-se de cinco a dez conceitos e palavras-chave que darão forma à tradução icônica, gerando qualidades do signo para a passagem de uma linguagem a outra, possibilitando também a geração de metáforas que facilitarão o processo de tradução.

\subsection{Mídia}

A terceira etapa consiste na definição da mídia, é nesta fase que se aplica a contiguidade topológica e acontece a passagem do signo pelos diferentes meios. É necessário analisar detalhadamente as características da mídia escolhida, como o tamanho, definição, dinâmica, cores, material, estrutura, som e interatividade, pois estes implicarão diretamente nas etapas criativas.

A mídia a ser utilizada consiste em um brinquedo de encaixe, composto por um tapete em EVA de $60 \times 80 \times 7 \mathrm{~cm}$, seis peças táteis e de encaixe de diferentes formas geométricas com aproximadamente $21 \times 21 \mathrm{~cm}$, confeccionadas em uma impressora $3 \mathrm{D}$ e um recurso de áudio acionado por botões que funcionam através de um circuito microprocessado. Esses recursos possibilitam a tradução intersemiótica do conto "Os Três Porquinhos" do meio verbal para os meios táteis e auditivos e confirmam a contribuição da tradução intersemiótica e do design na elaboração de brinquedos pedagógicos que auxiliam na alfabetização e no letramento de crianças cegas.

\subsection{Painéis Semânticos}

Na quarta etapa, são criados os painéis semânticos nos quais as informações referenciais 
de cada signo serão organizadas. Os painéis são os primeiros elementos de representação icônica que aproximam a semelhança por qualidade, possibilitando a conexão dos dois lados da mensagem. São responsáveis pela representação visual dos conceitos-chave definidos na segunda etapa e podem ser construídos com imagens de revista, da internet, desenhos, materiais do cotidiano.

Para este projeto, foram elaborados três painéis semânticos com imagens e referências coletadas das pesquisas dos materiais relacionados na primeira etapa. O primeiro consiste em um apanhado de tecnologias e materiais possíveis de serem utilizados na confecção do brinquedo.

O segundo painel traz uma pesquisa de referências de produtos, dentre eles: livros, brinquedos e materiais utilizados por cegos de idades e situações diversas objetivando a gerar ideias para a elaboração do protótipo.

E o terceiro painel é um compilado de elementos visuais das principais cenas que compõem a história, definindo o estilo, as formas e os ícones correspondentes ao conteúdo. $\mathrm{O}$ painel refere-se a uma tradução icônica, apresentando os elementos do conteúdo do roteiro, como por exemplo, os personagens dos três porquinhos, do lobo, as casinhas de palha, de madeira e de tijolos, buscando assim, uma referência para as formas e ilustrações.

A partir da pesquisa desenvolvida nesta etapa, foram selecionados alguns projetos como referência para a elaboração do protótipo. Dentre eles, pode-se destacar o brinquedo da empresa Reach\&Match que consiste em um tapete tátil com peças de encaixe e o projeto da fotógrafa Márcia Beal, de Porto Alegre que elaborou um álbum sensorial (com formas e texturas) para deficientes visuais.

\subsection{Geração de Alternativas}

A quinta etapa é a de geração de alternativas, nela se percebe a semelhança por justaposição nos aspectos visuais e materiais do processo de tradução. Com base nas informações coletadas, é definida uma tríade composta pelo conceitual, visual e material. No conceitual, defende-se o projeto e suas pré-definições. No visual, delimitam-se os tipos de grafismos utilizados no objeto traduzido, como exemplo, os rascunhos, desenhos, tipografias, ilustrações e etc. E, no material, faz-se a relação com o objeto tangível.

Seguindo a tríade proposta pelo autor, juntamente com os dados coletados, o projeto segue da seguinte forma:

a) Conceitual - Com a análise dos conceitos-chave e dos painéis semânticos das etapas anteriores, chegou-se ao conceito de um brinquedo didático-sensorial de conteúdo lúdico com foco na alfabetização e letramento de crianças cegas, buscando uma abordagem mais infantil e descontraída. O brinquedo segue a linha de um jogo de encaixe de peças, no qual a medida que são encaixadas com o auxílio das linguagens tátil e sonora, o usuário tem a possibilidade de compreender o conto literário infantil.

b) Visual - No que se refere ao aspecto visual, este projeto se estrutura em: esboços do produto e do sistema de acionamento, e reprodução do som e definição das ilustrações das cenas.

O esboço do produto e do sistema de transferência de som serviu como base para transmitir a ideia do produto aos envolvidos no projeto, uma vez que para a confecção do protótipo seria necessária a contribuição interdisciplinar de outros cursos. 
c) Material - O processo de materialização foi dividido em etapas e, para tal, foi necessário o envolvimento de outros profissionais, sendo dividido da seguinte forma:

- Gravação e edição do áudio: A gravação e edição do áudio da história para o desenvolvimento do produto foram feitas em conjunto com o Núcleo Multimídia da Faculdade SATC.

- Desenvolvimento do circuito microprocessado: Havia a necessidade de um circuito para o acionamento e a reprodução do som, dessa forma, com a contribuição do curso de Engenharia da Computação da Faculdade SATC e do LCA (Laboratório de Computação Aplicada) da Faculdade SATC, foi desenvolvido um circuito microprocessado.

- Desenvolvimento dos elementos e das cenas: o desenvolvimento das peças foi feito no Laboratório Pronto 3D - Laboratório de Prototipagem e Novas Tecnologias Orientadas ao 3D- e a ideia inicial era reproduzir as cenas de forma escultural em alto relevo no processo de fresagem em uma Fresadora Router CNC, porém, o equipamento não possuía uma ponteira de milimetragem equivalente para reproduzir os detalhes da imagem.

- Na sequência, fez-se uma tentativa de reprodução em uma impressora 3D, mas as imagens vetorizadas não alcançaram os objetivos propostos. Para alcançar o resultado desejado, as imagens deveriam ter um estilo fotográfico, para serem adaptadas em um software que possibilitasse sua passagem para o 3D, porém, os desenhos já haviam sido definidos num estilo infantil e não havia tempo hábil para refazê-los.

- Para conseguir materializar o produto, optou-se então por fazer os personagens e elementos em MDF de $3 \mathrm{~mm}$ cortados a laser, colando-os nas bases geométricas e aplicando materiais diversos para simular as texturas originais. Dentre os materiais: pelo sintético para a pele do lobo; E.V.A. texturizado para a pele dos porcos; feltro para as roupas dos porcos; palha de milho para confeccionar a casa de palha, olhos de boneca para todos os personagens e meias pérolas para fazer a numeração em braille. Na casa de madeira, optou-se pelo material original e nas casas de tijolos foi realizada uma texturização manual com estilete e lixas.

- Desenvolvimento da base do brinquedo: o brinquedo possuía seis peças de encaixe que necessitavam de uma base para serem encaixadas. Na confecção dessa base, optou-se por duas placas de E.V.A. de $60 \times 80 \times 1,5 \mathrm{~cm}$, na qual a primeira era vazada nas formas geométricas das peças e do alto-falante e a segunda fazia a função de fundo e apoio à micro chave encarregada de acionar o sinal elétrico que será interpretado pela Placa Arduíno UNO R3. Para comportar essas placas e acomodar todo o circuito microprocessado, fez-se uma caixa em MDF de 60x80x7cm.

\subsection{Solução e Validação}

De acordo com Medeiros et al. (2016), a sexta e última etapa é a de solução e validação, que faz referência com a semelhança por mediação. Nessa etapa, as alternativas apontam para uma única escolha, gerando um resultado final que será validado pelo público alvo fornecendo o feedback necessário para a execução do projeto. No projeto, essa etapa foi dividida em dois momentos: o primeiro é a solução do projeto e finalização do protótipo; o segundo refere-se à validação realizada com o produto finalizado.

Solução: concluído o processo de geração de alternativas e selecionando os melhores resultados, seguiu-se para a montagem final do protótipo que consistiu na junção da gravação do áudio, do circuito microprocessado, dos elementos das cenas e da base do brinquedo conforme 
apresenta a Fig. 2.

Figura 2 - Etapas de montagem
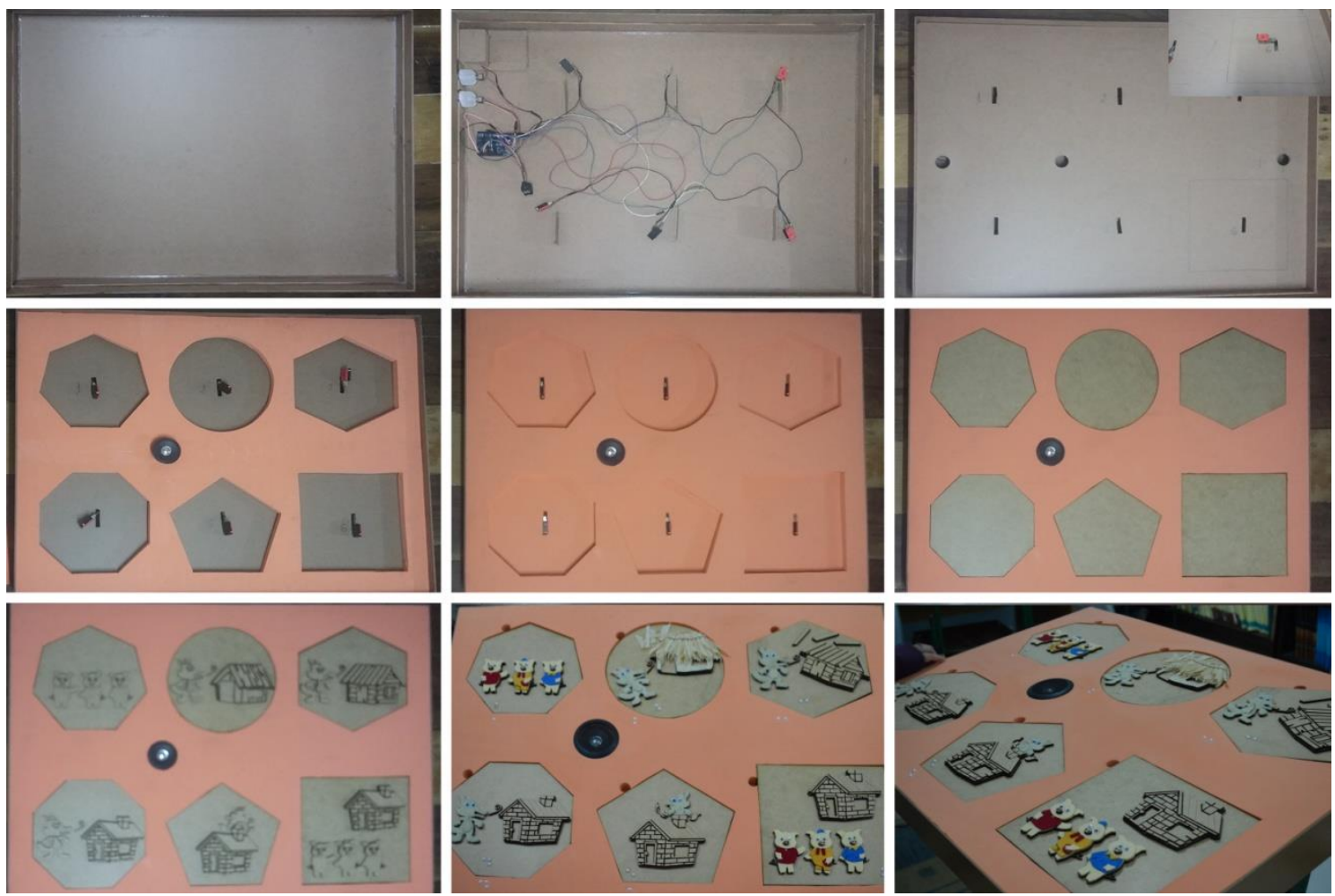

Fonte: o autor

Após a montagem e conclusão do protótipo, seguiu-se para a etapa de validação com o público-alvo.

Validação: esta etapa objetiva recolher o feedback do protótipo, buscando a validação do projeto e gerando material de estudo para futuras produções na área.

A validação do protótipo foi feita na Escola Básica São Cristóvão, no dia dezenove de outubro do ano de dois mil e dezessete, às oito horas e trinta minutos, com o apoio da professora Daiana, permitindo a aplicação do brinquedo em sala de aula com dois alunos.

Estavam presentes na sala de aula a professora, a autora da pesquisa, dois voluntários e os dois alunos. Inicialmente, fez-se uma breve explicação do projeto à professora que, na sequência, iniciou a aplicação do brinquedo com os alunos que foram receptivos quanto à experiência e contribuíram para os resultados obtidos.

Por se tratar de uma pesquisa de abordagem qualitativa, na qual não é possível quantificar os resultados através de cálculos ou números, estes foram embasados na análise comportamental e nas características subjetivas coletadas mediante a aplicação do teste que serão detalhadas na análise e discussão de resultados. 


\section{Análise e Discussão dos Resultados}

O estudo tinha como foco crianças e adolescentes com total ausência de visão, em idade de alfabetização e letramento, visava ainda a proporcionar o conhecimento do gênero discursivo conto de forma lúdica. Dessa forma, foi fundamental a busca por uma escola com alunos nesse perfil para a aplicação e validação do projeto.

Figura 3 - Imagens do teste
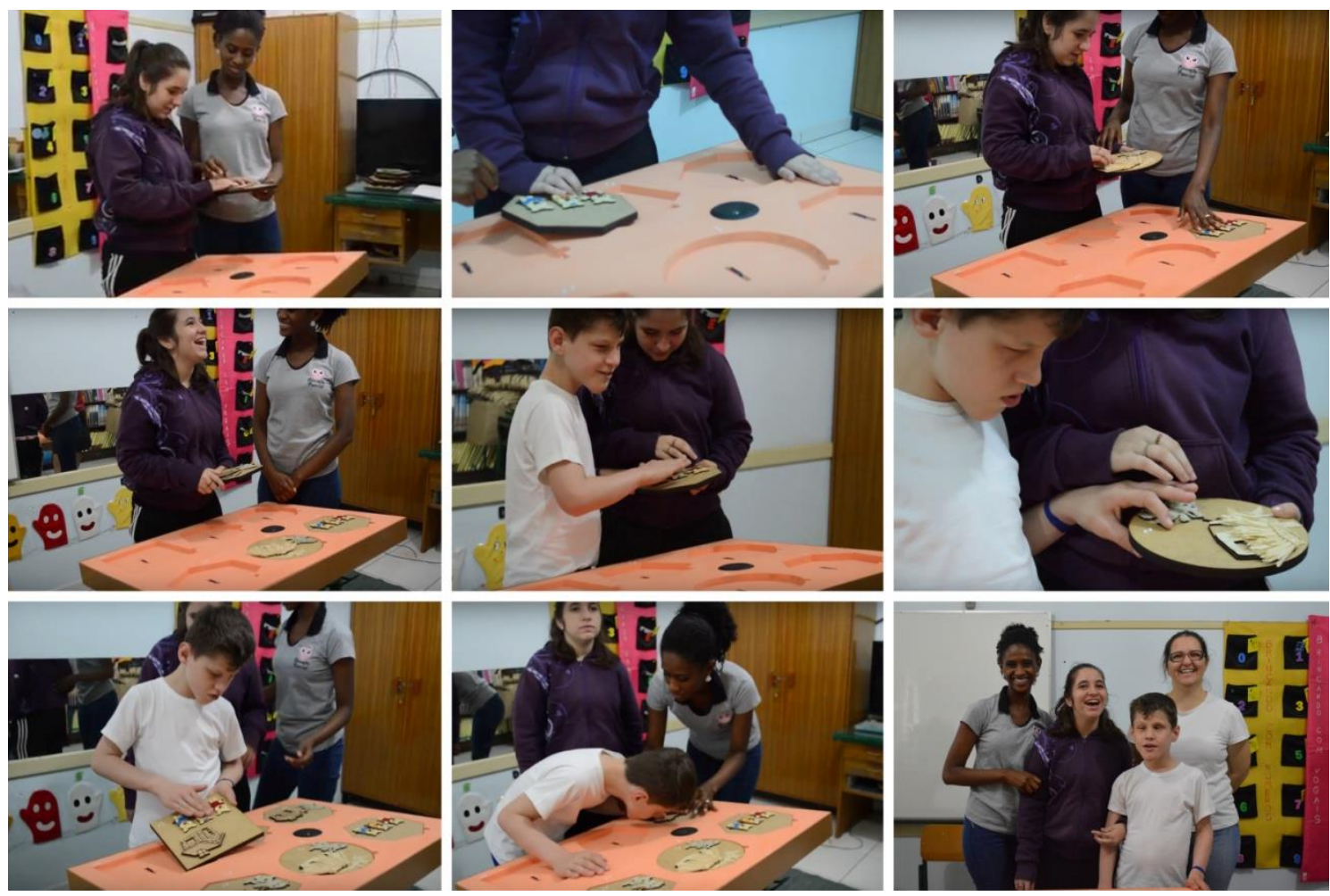

Fonte: o autor

A ideia inicial do projeto era a de que com o auxílio da professora os alunos pudessem interagir com o brinquedo pedagógico, de modo que o objeto pudesse auxiliar no aprendizado do conto infantil e no processo de alfabetização e letramento. Sendo assim, inicialmente foi explicado o processo de aplicação do teste à professora, já que seria aplicado por ela.

O teste foi realizado isoladamente com duas crianças, devido ao fato de ser este o número de crianças cegas na escola, uma menina e um menino de catorze e dez anos, respectivamente.

O teste inicial foi realizado com a menina que nasceu cega, porém, tem a percepção da luz e já é alfabetizada em braille. No momento que ela recebeu a primeira peça do brinquedo, ficou atraída pela riqueza de detalhes da cena e não se ateve à forma geométrica e ao que ela deveria fazer. Na sequência, com a ajuda da professora, que indicou a base de encaixe, as formas e a numeração em braille que ordenava cada peça correspondente ao local do encaixe, a menina conseguiu encaixar a primeira peça e as demais sucessivamente.

O fato de ela ter conhecimento do conto "Os Três Porquinhos" facilitou a identificação das 
cenas, das texturas e dos personagens. Ela conseguiu identificar as texturas das peles dos personagens mencionando que eram peludinhos e fofinhos. Identificou ainda a textura das casinhas, em especial a de palha, os olhos como sendo de bonecas e, até mesmo a forma espiral que simulava o sopro do lobo mau.

Também foram mostradas à menina duas outras peças elaboradas em processos diferentes: a primeira foi uma peça realizada na impressora 3D e a segunda foi uma simulação em massa adesiva tipo Durepox, do processo de fresagem da Fresadora Router CNC. Com relação a essas duas opções, ela mencionou que a primeira opção era ruim, que parecia plástico e não facilitava a identificação das formas e a segunda era legal, mas que preferia ainda as peças originais por possuírem maior riqueza de detalhes e texturas.

O segundo teste foi realizado com o menino, que nasceu cego, possui também um grau leve de autismo e ainda não é alfabetizado em braille. Para o teste, por se tratar de uma criança autista, a professora contou com a colaboração da menina por serem amigos e representar segurança para o menino no momento da brincadeira.

Com o garoto, o processo foi mais lento e, quando ele recebeu a primeira peça, mencionou os personagens como sendo dinossauro e cachorro, mas com o auxílio da menina, começou a recordar da história e dos personagens por também conhecer o conto. Também conseguiu encaixar todas as peças, sentiu as texturas, mas se ateve muito ao som e ao olfato. Em muitos momentos, pediu para escutar a história e cheirou as peças.

Foi possível perceber a satisfação das crianças com relação ao brinquedo, em especial para a menina, que teve reações positivas e mencionou várias vezes querer ter um brinquedo semelhante em casa. A professora ressaltou a importância do trabalho na visão pedagógica em vários aspectos como: o lúdico, no qual as crianças aprendem brincando; o desenvolvimento da motricidade por meio do encaixe das formas; o desenvolvimento cognitivo, visual, do raciocínio lógico e de curto prazo; e mencionou que o brinquedo também pode ser usado por crianças videntes e na alfabetização e letramento de crianças com outras deficiências como o autismo, o TDH, dentre outras.

O ponto negativo dessa etapa está relacionado ao fato de o número de crianças que participaram do teste ser pequeno. O ideal seria testar com um número maior de participantes, porém, todos os envolvidos superaram as expectativas e contribuíram para traduzir intersemioticamente o conto "Os Três Porquinhos" por meio da elaboração de um brinquedo destinado ao letramento de crianças cegas.

Este estudo cumpre seu objetivo de elaborar um brinquedo destinado ao processo de alfabetização e letramento de crianças cegas a partir da tradução intersemiótica do conto "Os Três Porquinhos", alcançando, dessa forma, os objetivos gerais e específicos.

Além de confirmar a tradução intersemiótica como transcrição das formas por meio das texturas e formas dos personagens e elementos, e a tradução intersemiótica como intercurso dos sentidos quando por meio do tato e audição as crianças puderam interagir e reconhecer o conto.

Sugere-se a continuidade do estudo e a aplicação do teste com um número maior de crianças, já que o projeto possibilita outras pesquisas nas diversas áreas que envolvem o design gráfico, além de nortear soluções futuras para a alfabetização e o letramento de crianças cegas por se tratar de uma ferramenta auxiliar do professor em sala de aula. 
O estudo ainda abre caminho para a tradução intersemiótica de outras obras literárias e para o desenvolvimento de novos brinquedos didático-pedagógicos.

\section{Referências}

ALMEIDA, Maria da Glória. Alfabetização da criança cega: uma reflexão necessária. Disponível em: <http://www.deficienciavisual.pt/txt-alfabetizacao_crianca_cega.htm>. Acesso em: 11 set. 2017.

CADEMARTORI, Ligia. O que é literatura infantil. 6.ed. São Paulo: Brasiliense, 1994.

FERREIRA, Caroline Nascimento; SANTOS, Gabriela Damásio dos. Design Lúdico: definições de uma estrutura interativa. Disponível em: <http://www.ufrgs.br/ped2014/trabalhos/trabalhos/833_arq2.pdf >. Acesso em: 12 dez. 2017.

IBGE. Instituto Brasileiro de Geografia e Estatística. Censo Demográfico 2010. Disponível em: <http://www.ibge.gov.br/home/presidencia/noticias/noticia_visualiza.php?

id_noticia=2018\&id_pagina=1>. Acesso em: 11 nov. 2016.

JAKOBSON, Roman. Linguística e comunicação. 26 ed. São Paulo: Cultrix, 2011.

MALUF, Angela Cristina Munhoz. Atividades lúdicas para Educação Infantil: conceitos, orientações e práticas. Petrópolis: Vozes, 2008.

MARQUES, Cristina. Clássicos de ouro: Os Três Porquinhos. 3 ed. Blumenau: Todolivro, 2015.

MEDEIROS, Diego Piovesan; TEIXEIRA, Felipe; GONÇALVES, Marília Matos. Metodologia de tradução Intersemiótica aplicada ao design gráfico. Revista Vincci, [S.I.], p. 23-38, jul. 2016. Disponível em:<http://revistavincci.satc.edu.br/ojs/index.php/Revista- Vincci/article/view/48>. Acesso em: 10 out. 2017.

MINISTÉRIO DA EDUCAÇÃO (MEC). Elementos conceituais e metodológicos para definição dos direitos de aprendizagem e desenvolvimento do ciclo de alfabetização (10, 20 e 30 anos) do ensino fundamental. $2012 . \quad$ Disponível em: <http://portal.mec.gov.br/component/docman/?task=doc_download\&gid=12827\&ltemid=>. Acesso em: 26 out. 2017.

. Lei no 9.394 de 20 de dezembro de 1996. Lei de Diretrizes e Bases da Educação Nacional. 1996. Disponível em: <http://portal.mec.gov.br> Acesso em: 28 set. 2017.

NIEMEYER, Lucy. Elementos da semiótica aplicados ao design. Rio de Janeiro: 2AB, 2009.

ORGANIZAÇÃO MUNDIAL DA SAÚDE (WHO). Action plan for the prevention of avoidable blindness and visual impairment. 2009-2013.Disponível em: <http://bit.ly/1oqAc9z>. Acesso em: 11 nov. 2016.

PEIRCE, Charles Sanders. Semiótica. 3 ed. São Paulo: Perspectiva, 2010.

PLAZA, Julio. Tradução intersemiótica. 2 ed. São Paulo: Perspectiva, 2016.

PRETO, Vivian de Oliveira. Adaptação de livros de literatura infantil para alunos com deficiência visual. 2009. 237 f. Dissertação (mestrado) - Universidade Estadual Paulista, Faculdade de Filosofia e Ciência, 2009. 
SANTAELLA, Lúcia. O que é semiótica. São Paulo: Brasiliense, 1983.

SCHEFFER, Cristiane Sebastião. A literatura no contexto da educação infantil. 2010. Trabalho apresentado para a obtenção de Licenciatura em Pedagogia à Distância. Rio Grande do Sul, Brasil: Universidade Federal do Rio Grande do Sul.

SOARES, Magda. Alfabetização e letramento. 6 ed. São Paulo: Contexto: 2013.

TFOUNI, Leda Verdiani. Letramento e alfabetização. 5 ed. São Paulo: Cortez, 2002. 